\title{
Laxity measurement of internal knee rotation after primary anterior cruciate ligament rupture versus rerupture
}

\author{
Hermann O. Mayr ${ }^{1}$ (D) $\cdot$ Georg Hellbruegge ${ }^{2} \cdot$ Florian Haasters $^{3} \cdot$ Bastian Ipach $^{2} \cdot$ Hagen Schmal $^{1} \cdot$ Wolf C. Prall $^{3}$
}

Received: 2 August 2021 / Accepted: 16 November 2021 / Published online: 6 December 2021

(c) The Author(s) 2021

\begin{abstract}
Purpose The aim of the current study was to objectify the rotational laxity after primary anterior cruciate ligament (ACL) rupture and rerupture after ACL reconstruction by instrumented measurement. It was hypothesized that knees with recurrent instability feature a higher internal rotation laxity as compared to knees with a primary rupture of the native ACL.

Study design Cross-sectional study, Level of evidence III.

Methods In a clinical cross-sectional study successive patients with primary ACL rupture and rerupture after ACL reconstruction were evaluated clinically and by instrumented measurement of the rotational and antero-posterior laxity with a validated instrument and the KT1000 ${ }^{\circledR}$, respectively. Clinical examination comprised IKDC 2000 forms, Lysholm Score, and Tegner Activity Scale. Power calculation and statistical analysis were performed ( $p$ value $<0.05$ ).

Results 24 patients with primary ACL rupture and 23 patients with ACL rerupture were included. There was no significant side-to-side difference in anterior translation. A side-to side difference of internal rotational laxity $\geq 10^{\circ}$ was found significantly more frequent in reruptures $(53.6 \%)$ compared to primary ruptures $(19.4 \% ; p<0.001)$. A highly significant relationship between the extent of the pivot-shift phenomenon and side-to-side difference of internal rotation laxity could be demonstrated $(p<0.001)$. IKDC 2000 subjective revealed significantly better scores in patients with primary ACL tear compared to patients with ACL rerupture $(56.4 \pm 7.8$ vs. $50.8 \pm 6.2 ; p=0.01)$. Patients with primary ACL tears scored significantly better on the Tegner Activity Scale $(p=0.02)$. No significant differences were seen in the Lysholm Score $(p=0.78)$.

Conclusion Patients with ACL rerupture feature significantly higher internal rotation laxity of the knee compared to primary ACL rupture. The extend of rotational laxity can be quantified by instrumented measurements. This can be valuable data for the indication of an anterolateral ligament reconstruction in ACL revision surgery.
\end{abstract}

Keywords Rotational laxity $\cdot$ Instrumented measurement $\cdot$ ACL $\cdot$ Anterior cruciate ligament $\cdot$ Rerupture $\cdot$ Anterolateral ligament $\cdot$ ALL

Hermann O. Mayr

hermann.mayr@uniklinik-freiburg.de

1 Department of Orthopedic and Trauma Surgery, University Hospital, Albert Ludwig University of Freiburg, Hugstetter Str. 55, 79106 Freiburg, Germany

2 Schoen Clinic Munich Harlaching, Academic Teaching Hospital Munich University, Munich, Germany

3 Department of General, Trauma and Reconstructive Surgery, University Hospital, Ludwig-Maximilians-University Munich, Munich, Germany

\section{Introduction}

Injuries with tears of the anterior cruciate ligament (ACL) result in anterior to posterior (a.p.) translational and internal rotational instability of the knee joint. The extend of internal rotational laxity depends on individual anatomical characteristics (general joint laxity [37], tibial slope, femoral condyle shape [37], and mechanical alignment) as well as the traumatic lesions of anterolateral and intraarticular structures [menisci, iliotibial band, Kaplan fibers, capsule, and the anterolateral ligament (ALL)]. The ALL is a crucial peripheral rotational stabilizer of the knee joint [7, 8, 33], and has increasingly been investigated on in clinical context over the last years $[10,34,41,48,49]$. In cases of pronounced anterolateral rotational instability of the knee joint, 
a growing number of publications postulate a simultaneous reconstruction of the ALL and the ACL $[15,16,22,32$, $36,38]$. Various operative techniques have been proposed $[13,15,19,35,43]$. Knees with persistent internal rotational instability may be more prone to suffer a reruptur secondary to the ACL reconstruction as ongoing pivot-shift phenomenon and rotational laxity has been shown to correlate with inferior clinical outcome [3, 23]. Thus, some authors hypothesized that poor rotational control may predispose patients to future graft failure and need for revision surgery.

Unfortunately, there is a lack of evidence-based treatment algorithms and consensus within the orthopedic community regarding the rotational laxity in primary and recurrent ACL ruptures. One of the underlying problems is that the objective and standardized determination of the internal rotational instability is still difficult. The clinical evaluation encompasses the dial and pivot-shift test. These tests are rater-dependent and influenced by knee position as well as examiner-induced motion. Consequently, the interrater reliability of the manual examination methods is limited [29, $39,40]$. Some of the instrumented measurements require an elaborate set-up including fluoroscopic $[28,30]$ or magnetic resonance imaging $[11,12]$. Other torsion measurements apply the torque to the foot without locking the ankle, which can lead to a considerable overestimation of the rotational laxity $[2,44]$.

The aim of the current study was to objectify the rotational knee laxity with a validated measurement method, the combined measurement of internal rotation and anteroposterior (a.p.) translation [26], and to compare primary ACL ruptures with recurrent instabilities after previous ACL reconstruction. It is hypothesized that knees with a recurrent instability secondary to ACL reconstruction feature a larger internal rotation laxity than knees with a primary ACL rupture.

\section{Materials and methods}

This clinical comparative study was conducted investigating patients with primary ACL rupture and patients with ACL rerupture secondary to ACL reconstruction. Knee joints were evaluated clinically and by instrumented measurement of the internal rotational laxity and antero-posterior laxity with a validated Instrument Laxitester ${ }^{\circledR}$ (ORTEMA Sport Protection, Markgroeningen, Germany) and KT1000 ${ }^{\circledR}$ (MEDmetric Corporation, San Diego, CA) [26], respectively (Fig. 1). Included were voluntary consecutive patients of the clinic with primary unilateral ACL rupture and patients with ACL rerupture, 20-55 years of age, ASA classification I or II and a BMI of 18-30 after differentiated information and counseling. Exclusion criteria were collateral ligament instabilities $>\mathrm{I}^{\circ}(2-5 \mathrm{~mm})$, additional posterior instabilities,

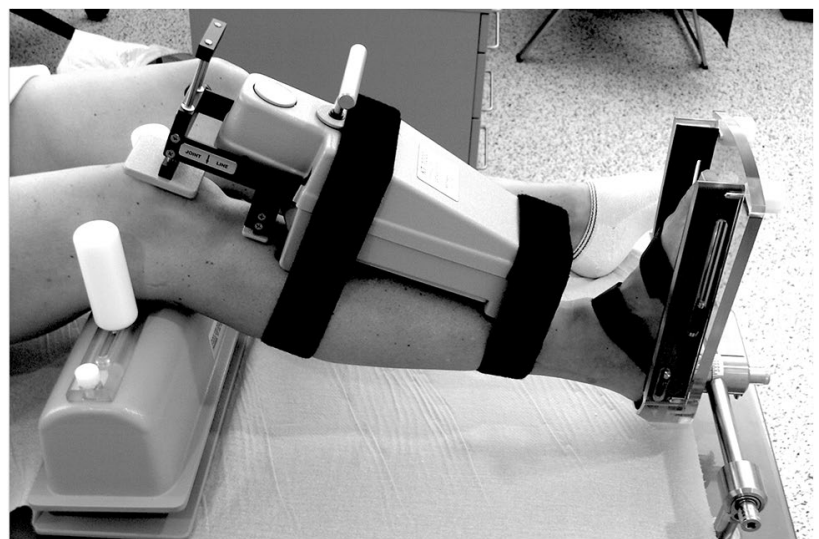

Fig. 1 The rotational knee laxity was measured with a validated instrument $\left(\right.$ Laxitester $\left.^{\circledR}\right)$. The femur was fixed at a knee flexion angle of $30^{\circ}$ by medial and lateral counter-bearings at the femoral epicondyles. The foot was fixed in a precisely adjustable footplate. The ankle was locked by dorsiflexion using the trapezoidal shape of the talus. Rotation of the lower leg was performed by torque on the footplate. Under these conditions, the torque applied to the foot is transmitted to the lower leg (25)

axis deviation (varus or valgus) of more than $5^{\circ}$, and knee osteoarthritis grade 2 or higher according to the Kellgren and Lawrence classification [21].

The clinical data were assessed utilizing the IKDC 2000 subjective form, the Lysholm Score, and the Tegner Activity Scale $[17,20]$. Conventional X-rays in two planes, a tangential view of the patella in $45^{\circ}$ knee flexion and a long leg standing radiograph were made in terms of the group's clinical routine and in addition to the clinical examination. The clinical examination encompassed a thorough evaluation of the collateral and the posterior cruciate ligaments in order to screen for exclusion criteria. With regard to the aim of the study, the pivot shift phenomena were determined subdividing the grades of laxity glide $(+)$, clunk $(++)$, and gross $(+++)$. The clinical examination was carried out by two independent orthopedic and trauma surgeons with specific experience of more than ten years. The investigators were blinded. The study was conducted as a single centre study and the patients were examined in the outward patient clinic of the group's hospital.

The rotational knee laxity was measured with a validated Instrument (Laxitester ${ }^{\circledR}$, Fig. 1). The femur was fixed at a knee flexion angle of $30^{\circ}$ by medial and lateral counterbearings at the femoral epicondyles. The foot was fixed in a precisely adjustable footplate. The ankle was locked by dorsiflexion using the trapezoidal shape of the talus. Rotation of the lower leg was performed by torque on the footplate. Under these conditions, the torque applied to the foot is transmitted to the lower leg. Internal and external rotation angles of the lower leg were determined with a torque of 2 $\mathrm{Nm}$. The previous validation study showed that a torque of 
more than two Nm is perceived as painful by the patient even if the knee is not irritated and leads to increased muscular tension. The accuracy of the device has been described to be $5^{\circ}$ [26]. In addition, a.p. translation was measured using the $\mathrm{KT} 1000^{\circledR}$ Arthrometer in neutral position of the lower leg as well as in internal and external rotation as previously described $[24,25]$. The a.p. translation was conducted with the leg being fixed in the Laxitester ${ }^{\circledR}$. In order to allow for comparison with other instrumented studies and to exclude pretensioning of the gastrocnemius muscle, the a.p. translation was measured in a neutral ankle position. All other measurements were performed in a defined dorsiflexion of the ankle [26]. The instrumented measurements were conducted by a single investigator (G.H.). Each rotation measurement was carried out and recorded 3 times. All values are listed in Table 4. The mean of the side-to-side difference and the standard deviation were included in the further calculation. The side-to-side difference of the internal rotation angle of the knee joint under $2 \mathrm{Nm}$ torque was set as the primary endpoint. Secondary endpoints were the grading of the pivot-shift phenomenon, the a.p. translation measured by the KT $1000^{\circledR}$ Arthrometer, the IKDC 2000 subjective form, the Lysholm Score, and the Tegner Activity Scale.

\section{Statistical evaluation}

Means and standard deviations were calculated for all numeric values. The Kolmogorov-Smirnov test was applied to check for normal distribution. In order to test for significance, the Student's $t$ test was applied for numeric variables. The chi-square test was used to test for significant differences in distribution of categorical variables. The Spearman's correlation coefficient $\left(r_{\mathrm{s}}\right)$ was calculated to measure the strength of a linear correlation between two variables. Cohen's kappa coefficient $(K)$ war used to measure inter-rater reliability for categorical items. The Pearson's correlation coefficient $(r)$ was applied to measure of the degree of linear relationship between sets of numeric variables.

Power calculation: With a significance level of 5\% for two-sided testing, a power of $80 \%$ and an expected difference of $10^{\circ}$ with a standard deviation of $10^{\circ}, 20$ test subjects per group are required to obtain a statistically significant difference in the internal rotation angle of the knee joint in the side-to-side comparison. Differences with a $p$ value $<0.05$ were regarded as statistically significant. Data analysis was performed by SPSS ${ }^{\circledR}$ statistical software version Premium 26 (SPSS, Chicago, USA).

\section{Institutional review board approval}

Freiburg University authorities gave the application number EK-Freiburg 542/19 the institutional review board (IRB) approval on February 25, 2020.

\section{Results}

\section{Study cohorts}

Twenty-four patients with primary ACL rupture and 23 patients with rerupture after ACL reconstruction were included in this clinical comparative study. None of the patients that qualified for inclusion declined consent and participation. The patients' demographics and injury data are presented in Table 1. The distribution of meniscus and cartilage damage in both groups is shown in Tables 2 and 3.
Table 1 Patients' demographics and injury data

\begin{tabular}{lll}
\hline & $\begin{array}{l}\text { Primary ACL } \\
\text { rupture }(n=24)\end{array}$ & ACL rerupture $(n=23)$ \\
\hline Age (years) & $31.3( \pm 9.1)$ & $31.2( \pm 6.7)$ \\
Gender (m: f) & $14: 10$ & $13: 10$ \\
Injury mechanism & Soccer $=8$ & Adequate trauma (sport injury, acci- \\
& Ski alpine $=5$ & dent, fall, etc. $)=10$ \\
& Handball $=3$ & Inadequate trauma (an incident dur- \\
& Accident $=3$ & ing minor movement or everyday \\
& Fall $=2$ & stress $)=5$ \\
& Others $=3$ & Chronic instability (no history of a \\
& & specific incident $)=8$ \\
Clinical evaluation & $n=19$ & $n=12$ \\
a) $\leq 180$ days after trauma & $n=3$ \\
b) $>180$ days after trauma & $n=5$ & $n=8$ \\
c)w/o history of trauma & $n=0$ & \\
Interval trauma-clinical evaluation in & $58.8( \pm 34.0)$ & $50.8( \pm 47.5)$ \\
group a) (days) & & \\
\hline
\end{tabular}

$m$ male, $f$ female

${ }^{\mathrm{a}}$ Encompasses adequate and inadequate traumata in the group of ACL rerupture 
Table 2 The distribution of meniscus damage in both groups

\begin{tabular}{lccccc}
\hline Meniscal lesion & \multicolumn{2}{l}{$\begin{array}{l}\text { Primary ACL rupture } \\
(n=24)\end{array}$} & & \multicolumn{2}{l}{$\begin{array}{l}\text { Rerupture after } \\
\text { ACLR }(n=23)\end{array}$} \\
\cline { 2 - 3 } \cline { 6 - 7 } \cline { 6 - 7 } & Medial & Lateral & & Medial & Lateral \\
\hline None & 18 & 13 & & 12 & 16 \\
Moderate & 3 & 5 & & 4 & 2 \\
Severe & 3 & 6 & & 7 & 5 \\
\hline
\end{tabular}

In the rerupture group a previous suture or a partial resection of the medial meniscus was evident in two and eight cases, respectively. With regards to the lateral meniscus, a previous suture or a partial resection was evident in three and two cases, respectively. Patients with primary ACL rupture showed no significant age difference compared to patients with ACL rerupture $(31.3 \pm 9.1$ and $31.2 \pm 6.7$ years, $p=0.98)$. No significant difference in gender distribution was detected $(p=0.9)$. Both groups encompassed a limited number of patients with delayed presentation after the trauma (primary ACL rupture $=5$; ACL rerupture $=3$ ). With regards to those patients presenting within 6 months after the trauma, no significant differences were found in the interval between trauma and clinical evaluation across the two groups $(58.8 \pm 34.0$ and $50.8 \pm 47.5$ days; $p=0.58)$. Each rotation measurement was carried out and recorded 3 times. All values are listed in Table 4.

\section{Instrumented measurement of anterior and internal rotational laxity}

The side-to-side difference in anterior translation was measured by means of the $\mathrm{KT} 1000^{\circledR}$ and revealed $4.0 \pm 1.7 \mathrm{~mm}$ in patients with primary ACL rupture as well as $4.0 \pm 1.8 \mathrm{~mm}$ in patients with ACL rerupture. This difference was statistically not significant $(p=1.0)$. In contrast, a significant side-to-side difference of internal rotation angles was found with a mean of $8.7 \pm 8.6^{\circ}$ in patients with ACL rerupture as compared to a mean of $3.6 \pm 4.5^{\circ}$ in patients with primary ACL rupture ( $p=0.014 ;$ Fig. 2 ). A significant side-to-side difference of external rotation angles was not seen across the two groups ( $p=0.18$; Fig. 2 ). The individual rotation measurements are provided in Table 2 . The relationship between the rotation measurements showed a strong positive correlation with a Pearson correlation coefficient of $r=0.847$. A side-to-side difference of internal rotational laxity $\geq 10^{\circ}$ was found significantly more frequent in patients with ACL rerupture as compared to patients with primary ACL rupture with $53.6 \%$ versus $19.4 \%$ of the measurements, respectively $(p<0.001)$.

\section{Pivot-shift phenomenon}

All patients of both groups revealed a positive pivot-shift test for the injured knees. The distribution of the grades of the pivot-shift phenomenon showed significant differences between patients with primary ACL tears and ACL rerupture $(p<0.001)$.

In patients with primary ACL tears pivot-shift glide $(+)$ was found in 38 tests, pivot-shift clunk $(++)$ in 9 tests, and pivot-shift gross $(+++)$ in 1 test as compared to 18,21 , and 7 tests in the group of ACL reruptures, respectively. Cohen's weighted $K$ (quadratically) calculated for the pivotshift result of two raters on 47 cases resulted in a $K=0.445$ as sign for a moderate agreement. A highly significant relationship between the extent of the pivot-shift phenomenon and side-to-side difference of internal rotation could be demonstrated (primary ACL tear $\mathrm{r}_{\mathrm{s}}=0.695 ; p\left(R^{2}\right)<0.001$; ACL rerupture: $\left.\mathrm{r}_{\mathrm{s}}=0.637 ; p\left(R^{2}\right)<0.001\right)$ (Fig. 3). No correlation was found between the amount of side-to-side difference of the anterior translation measured by KT1000® and the extend of side-to-side difference in internal rotational instability in patients with primary ACL ruptures $(\mathrm{R}=-0.284$; $\mathrm{p}=0.178)$ and patients with ACL rerupture $(R=0.367$; $p=0.086)$. Patients with a primary ACL tears scored significantly higher in the Tegner Activity Scale $(p=0.02)$ and the IKDC 2000 subjective questionnaire $(p=0.01)$ as compared to patients with an ACL rerupture. There was no significant difference in the Lysholm Score ( $\mathrm{p}=0.78)$ (Fig. 4).

$$
(R=-0.284 ; p=0.178)(R=0.367 ; p=0.086) \text {. }
$$

Table 3 The distribution of cartilage damage in both groups

\begin{tabular}{|c|c|c|c|c|c|c|}
\hline \multirow[t]{2}{*}{ Chondro-malacia } & \multicolumn{3}{|c|}{ Primary ACL rupture $(n=24)$} & \multicolumn{3}{|c|}{ Rerupture after ACLR $(n=23)$} \\
\hline & Medial & Lateral & PF & Medial & Lateral & $\mathrm{PF}$ \\
\hline 0 & 17 & 20 & 18 & 10 & 16 & 15 \\
\hline $\mathrm{I} / \mathrm{II}$ & 3 & 2 & 5 & 7 & 5 & 6 \\
\hline III & 4 & 2 & 1 & 4 & 2 & 2 \\
\hline IV & 0 & 0 & 0 & 2 & 0 & 0 \\
\hline
\end{tabular}


Table 4 Each rotation measurement was carried out and recorded 3 times

\begin{tabular}{|c|c|c|c|c|c|c|c|c|}
\hline \multirow[t]{2}{*}{ A } & \multicolumn{4}{|c|}{ Primary ACL rupture } & \multicolumn{4}{|c|}{ ACL rerupture } \\
\hline & 1 st run & 2nd run & 3 rd run & Mean & 1 st run & 2nd run & 3 rd run & Mean \\
\hline \multirow[t]{24}{*}{$\Delta \mathrm{IRO}$} & 0 & -5 & 5 & 0 & 10 & 5 & 15 & 10 \\
\hline & 0 & 0 & -5 & -1.7 & 15 & 15 & 20 & 16.7 \\
\hline & 0 & 0 & 5 & 1.7 & 0 & -5 & 5 & 0 \\
\hline & 0 & 5 & -5 & 0 & 5 & 0 & 10 & 5 \\
\hline & 0 & 5 & 0 & 1.7 & 10 & 15 & 0 & 8.3 \\
\hline & 5 & 10 & 5 & 6.7 & 5 & 10 & 0 & 5 \\
\hline & 0 & 5 & 5 & 3.3 & 15 & 10 & 20 & 15 \\
\hline & 0 & 0 & 0 & 0 & 25 & 30 & 20 & 25 \\
\hline & 5 & 10 & 0 & 5 & 0 & 0 & 5 & 1.7 \\
\hline & 0 & 5 & 0 & 1.7 & 0 & -5 & 5 & 0 \\
\hline & 0 & 0 & 5 & 1.7 & 10 & 15 & 5 & 10 \\
\hline & 10 & 10 & 15 & 11.7 & 0 & 5 & 0 & 1.7 \\
\hline & 0 & 0 & 5 & 1.7 & 10 & 10 & 15 & 11.7 \\
\hline & 10 & 10 & 5 & 8.3 & 10 & 15 & 10 & 11.7 \\
\hline & 0 & 0 & 0 & 0 & 0 & 0 & 0 & 0 \\
\hline & 10 & 15 & 5 & 10 & 0 & 5 & -5 & 0 \\
\hline & 0 & 0 & 0 & 0 & 10 & 10 & 5 & 8.3 \\
\hline & 15 & 15 & 20 & 16.7 & 35 & 30 & 40 & 35 \\
\hline & 5 & 5 & 0 & 3.3 & 10 & 5 & 5 & 6.7 \\
\hline & 0 & 0 & 5 & 1.7 & 0 & -5 & 0 & -1.7 \\
\hline & 5 & 0 & 5 & 3.3 & 15 & 10 & 10 & 11.7 \\
\hline & 0 & 0 & 0 & 0 & 5 & 10 & 10 & 8.3 \\
\hline & 0 & 0 & 5 & 1.7 & 10 & 10 & 10 & 10 \\
\hline & 10 & 5 & 10 & 8.3 & & & & \\
\hline Mean $( \pm S D)$ & $3.1( \pm 4.6)$ & $4.0( \pm 5.3)$ & $3.8( \pm 5.6)$ & $3.6( \pm 4.5)$ & $8.7( \pm 8.7)$ & $8.5( \pm 9.3)$ & $8.9( \pm 9.8)$ & $8.7( \pm 8.6)$ \\
\hline
\end{tabular}

The mean of the side-to-side difference and the standard deviation were included in the further calculation
A) $I R O$ internal rotation
B) $E R O$ external rotation

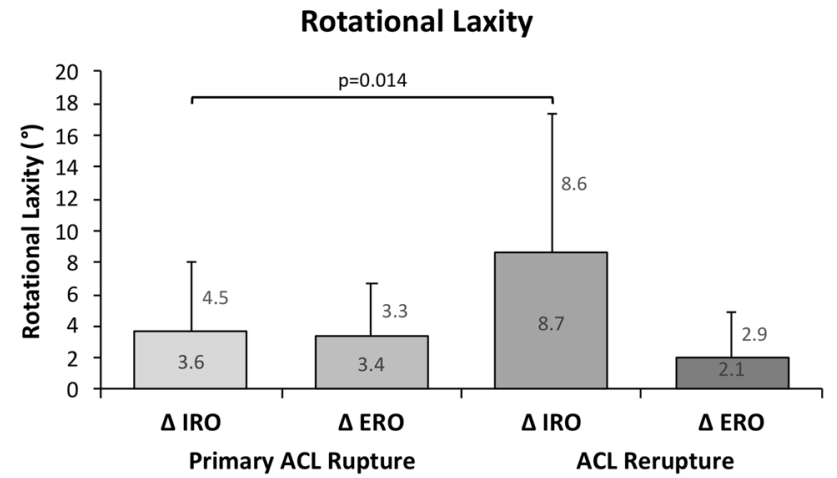

Fig. 2 A significant side-to-side difference of internal rotation laxity was found with a mean of $8.7 \pm 8.6^{\circ}$ in patients with an ACL rerupture as compared to a mean of $3.6 \pm 4.5^{\circ}$ in patients with a primary ACL rupture $(p=0.014)$. IRO internal rotation, $E R O$ external rotation

\section{Patients reported outcome measures (PROM)}

Patients with primary ACL tears scored significantly higher values in the Tegner Activity Scale with a mean of $3.5 \pm 0.8$ points compared to patients with ACL rerupture with a mean of $3.0 \pm 0.5$ points $(p=0.02)$. The IKDC 2000 subjective questionnaire revealed significantly better scores in patients with primary ACL tear compared to patients with ACL rerupture $(56.4 \pm 7.8$ vs. $50.8 \pm 6.2 ; p=0.01)$. No statistically significant differences were observed between patients with primary ACL tear and ACL rerupture when comparing the results of the Lysholm Score ( $66.2 \pm 14.3$ vs. $67.3 \pm 12.9$; $p=0.78$ ). 

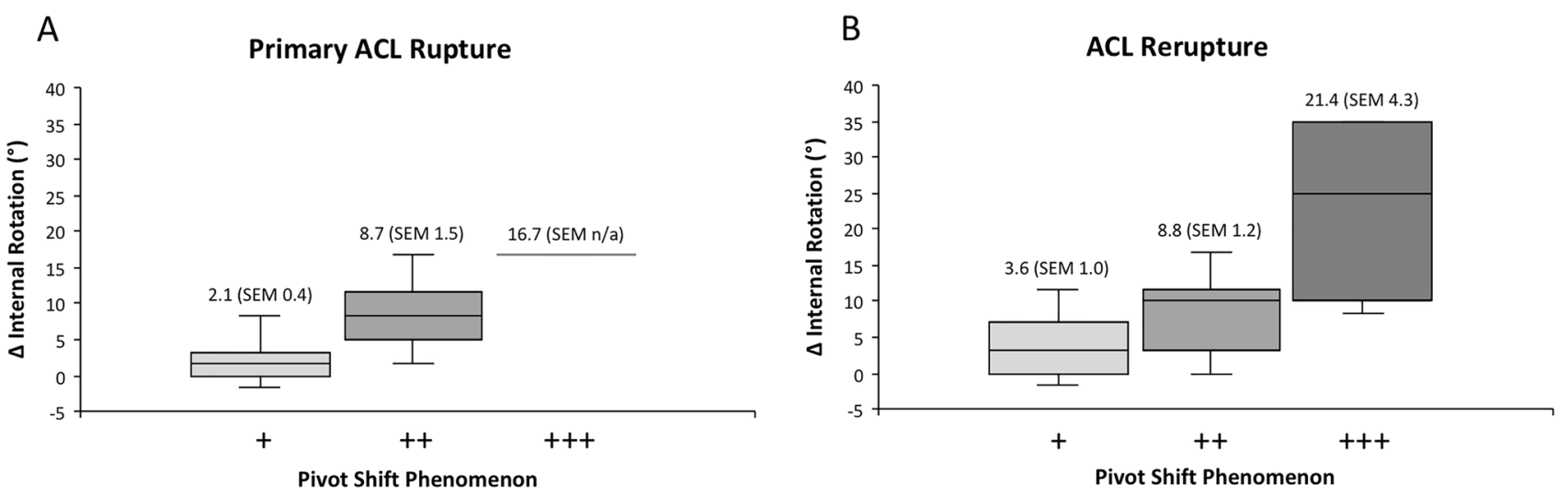

Fig. 3 A highly significant relationship between the extent of the pivot-shift phenomenon and side-to-side difference of internal rotation could be demonstrated (primary ACL tear $\mathrm{r}_{\mathrm{s}}=0.695 ; p\left(R^{2}\right)<0.001$; ACL rerupture: $\mathrm{r}_{\mathrm{s}}=0.637 ; p\left(R^{2}\right)<0.001$ )

\section{Discussion}

This is the first study revealing a significantly higher internal rotation laxity in knee joints with recurrent ACL rupture secondary to reconstruction compared to primary ruptures of the native ACL. The study further demonstrates that the Laxitester ${ }^{\circledR}$ (Fig. 1) is a feasible measuring device that allows for precise quantification of rotational laxity and reliable identification of patients with increased or excessive internal rotation instability. The repeated measurements show a strong positive correlation with a Pearson's correlation coefficient of $r=0.847$. In future, these instrumented measurements can help in decision making on which ACL reconstruction and revision may benefit from additional external anterolateral tenodesis.

The Laxitester ${ }^{\circledR}$ identifies increased internal rotation laxity in both, primary and recurrent ACL ruptures. However, across the two cohorts, the mean side-to-side difference of internal rotation laxity is significantly higher in the rerupture group $\left(8.7 \pm 8.6^{\circ}\right.$ vs. $3.6 \pm 4.5^{\circ}, p=0.014$; Fig. 2$)$. With regards to the primary ACL rupture, the present findings go well in line with Moewis et al., who reported a mean sideto-side difference of $5^{\circ}$ internal rotation laxity when comparing primary ACL ruptured and healthy knees exposed to a torque of $2.5 \mathrm{Nm}$ in $30^{\circ}$ flexion [28]. On the other hand, the physiological maximum side-to-side difference in healthy knees does not seem to exceed $1.5^{\circ}$ [1]. However, no study has yet systematically investigated the extend of internal rotational laxity after ACL rerupture secondary to ACL reconstruction.

For the purpose of this study, a side-to-side difference of $\geq 10^{\circ}$ of internal rotation laxity was thought to be clinically relevant. This cutoff was set in agreement with the previous publications on the dial test [40] and knee biomechanics [42, 44, 47] that also defined a side-to-side difference of $\geq 10^{\circ}$ as a pathologic internal rotation laxity. A side-to-side difference of internal rotational instability $\geq 10^{\circ}$ was found significantly more frequent in patients with ACL rerupture compared to patients with primary ACL rupture with $19.4 \%$ versus $53.6 \%$ of the measurements, respectively $(p<0.001)$. The increased internal rotation laxity is most likely a result of an additional injury to the anterolateral capsule and the ALL [15, 16, 32, 43]. Unfortunately, the incidence of additional relevant injuries to the ALL, in primary as well as in recurrent ACL ruptures, is still largely unknown. In contrast to the present findings revealed by instrumented laxity measurements, the magnetic resonance imaging (MRI) study by Carr et al. [5] did not find significant differences in the frequency of partly or completely torn ALL when comparing primary and recurrent ACL ruptures. Nevertheless, in both cases the incidence of lesions to the ALL was over 50\%. In general, such MRI findings do not reliably allow for conclusions on the actual clinical laxity.

The clinical evaluation of the extend of the pivot-shift phenomenon depends on the examiner and features limitations in the reliability. Noyes et al. [31] found that the magnitude of anterior subluxation varied greatly between examiners due to differences in the technical implementation. A meta-analysis of 28 studies showed that the pivotshift test has a high specificity of $98 \%$, but only a sensitivity of $24 \%$ [4]. In the present study the pivot-shift test carried by two blinded raters revealed a Cohen's weighted $K$ of 0.445 as sign for a moderate agreement.

Nevertheless, the present study revealed a strong correlation of the pivot-shift phenomenon and the instrumented laxity measurements (primary tear $\mathrm{r}_{\mathrm{s}}=0.695$; rerupture $\mathrm{r}_{\mathrm{s}}=0.637 ; p\left(R^{2}\right)<0.001$ in both groups). In patients with increased risk of failure, some groups base their indication for simultaneous ALL augmentation during primary ACL reconstruction on the grade of pivot-shift phenomenon [14, 16, 37, 43]. Taking a closer look at the present findings suggests a weaker correlation for the excessive 

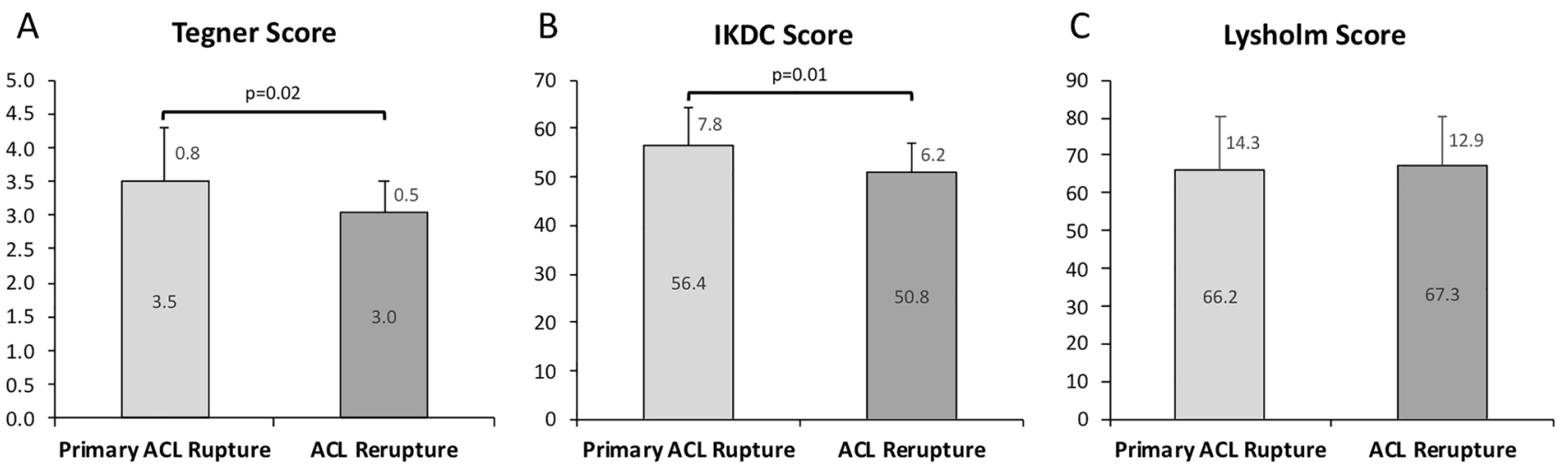

Fig. 4 Patients with a primary ACL tears scored significantly higher in the Tegner Activity Scale $(p=0.02)$ and the IKDC 2000 subjective questionnaire $(p=0.01)$ as compared to patients with an ACL rerupture. There was no significant difference in the Lysholm Score $(p=0.78)$

internal rotation laxity. While laxities beyond a gross pivot-shift phenomenon cannot be identified clinically, the Laxitester ${ }^{\circledR}$ further distinguishes excessive rotational laxity by providing numeric values. The sound inter- and intrarater agreement [26] and the precise numeric determination of the rotational laxity are clear strongpoints of the instrumented measurements. The Laxitester ${ }^{\circledR}$ reliably identifies patients with increased and excessive internal rotation laxity. These patients may benefit in particular from simultaneous ALL augmentation during primary or revision ACL reconstruction to further improve the rotational stability [45]. On the other hand, unnecessary simultaneous ALL augmentation in moderate internal rotational laxity can be avoided, thus, potentially reducing the phenomena of over-constrained stability observed in undifferentiated populations [6].

On average, the patients with a rerupture after ACL reconstruction score significantly lower on the Tegner Activity Scale and the IKDC 2000 subjective form when compared with primary ACL ruptures. The IKDC 2000 subjective questionnaire revealed a mean of $56.4 \pm 7.8$ in primary ACL tears compared to $50.8 \pm 6.2$ in ACL reruptures $(p=0.01)$. A recent systematic review and metaanalysis reported comparably low mean IKDC sores of 43.9 to 51.4 in patients with recurrent ACL rupture [9]. The differences in the Lysholm score did not reveal to be statistically significant between the two groups. While primary ACL tears showed a mean of $66.2 \pm 14.3$, ACL reruptures averaged in $67.3 \pm 12.9(p=0.78)$. This is comparable to Lysholm scores reported by Weiler et al., who revealed a mean value of $65 \pm 17$ in a cohort of 50 ACL reruptures [46]. In addition to the consensus, that lower PROM scores in patients with an ACL rerupture are due to higher numbers of previous operations as well as more pronounced wear and tear of menisci and joint surface cartilage [27], the present study indicates that lower
PROM scores may also, at least in part, be due to a higher extend of internal rotation laxity of the injured knee joint.

\section{Limitations}

Some general limitations of the present study result from the design of a clinical comparative study. A specific limitation is the KT $-1000^{\circledR}$, which had widely been utilized by knee surgeons and physiotherapists in the last decade [18], but which to today's standards is an outdated measuring device with limited accuracy. Another limitation is the accuracy of $5^{\circ}$ of the Laxitester ${ }^{\circledR}$.

\section{Conclusion}

Patients with ACL rerupture feature significantly higher internal rotation laxity of the knee compared to primary ACL rupture. The extend of internal rotation laxity can precisely be quantified by means of instrumented measurement. The quantification of internal rotational laxity can facilitate the decision-making process on simultaneous anterolateral ligament augmentation during revision ACL surgery.

Funding Open Access funding enabled and organized by Projekt DEAL. There is no funding source.

\section{Declarations}

Conflict of interest The authors declare that they have no conflict of interest.

Informed consent Informed consent was obtained from all individual participants included in the study. 
Open Access This article is licensed under a Creative Commons Attribution 4.0 International License, which permits use, sharing, adaptation, distribution and reproduction in any medium or format, as long as you give appropriate credit to the original author(s) and the source, provide a link to the Creative Commons licence, and indicate if changes were made. The images or other third party material in this article are included in the article's Creative Commons licence, unless indicated otherwise in a credit line to the material. If material is not included in the article's Creative Commons licence and your intended use is not permitted by statutory regulation or exceeds the permitted use, you will need to obtain permission directly from the copyright holder. To view a copy of this licence, visit http://creativecommons.org/licenses/by/4.0/.

\section{References}

1. Alam M, Bull AM, Thomas R, Amis AA (2013) A clinical device for measuring internal-external rotational laxity of the knee. Am J Sports Med 41(1):87-94

2. Almquist PO, Arnbjornsson A, Zatterstrom R, Ryd L, Ekdahl C, Friden T (2002) Evaluation of an external device measuring knee joint rotation: an in vivo study with simultaneous Roentgen stereometric analysis. J Orthop Res 20(3):427-432

3. Ayeni OR, Chahal M, Tran MN, Sprague S (2012) Pivot shift as an outcome measure for ACL reconstruction: a systematic review. Knee Surg Sports Traumatol Arthrosc 20(4):767-777

4. Benjaminse A, Gokeler A, van der Schans CP (2006) Clinical diagnosis of an anterior cruciate ligament rupture: a meta-analysis. J Orthop Sports Phys Ther 36(5):267-288

5. Carr JB 2nd, Yildirim B, Richter D et al (2018) Primary anterolateral ligament rupture in patients requiring revision anterior cruciate ligament reconstruction: a retrospective case-control magnetic resonance imaging review. Arthroscopy 34(11):3055-3062

6. Chen J, Wang C, Xu C et al (2021) Effects of anterolateral structure augmentation on the in vivo kinematics of anterior cruciate ligament-reconstructed knees. Am J Sports Med 49(3):656-666

7. Claes S, Luyckx T, Vereecke E, Bellemans J (2014) The segond fracture: a bony injury of the anterolateral ligament of the knee. Arthroscopy 30(11):1475-1482

8. Claes S, Vereecke E, Maes M, Victor J, Verdonk P, Bellemans J (2013) Anatomy of the anterolateral ligament of the knee. J Anat 223(4):321-328

9. Colatruglio M, Flanigan DC, Long J, DiBartola AC, Magnussen RA (2020) Outcomes of 1- Versus 2-Stage Revision Anterior Cruciate Ligament Reconstruction: A Systematic Review and Metaanalysis. Am J Sports Med:363546520923090

10. Eggeling L, Drenck TC, Frings J et al (2021) Additional lateral extra-articular tenodesis in revision ACL reconstruction does not influence the outcome of patients with low-grade anterior knee laxity. Arch Orthop Trauma Surg. https://doi.org/10.1007/ s00402-021-04145-y

11. Espregueira-Mendes J, Andrade R, Leal A et al (2017) Global rotation has high sensitivity in ACL lesions within stress MRI. Knee Surg Sports Traumatol Arthrosc 25(10):2993-3003

12. Espregueira-Mendes J, Pereira H, Sevivas N et al (2012) Assessment of rotatory laxity in anterior cruciate ligament-deficient knees using magnetic resonance imaging with porto-knee testing device. Knee Surg Sports Traumatol Arthrosc 20(4):671-678

13. Farthing C, Lang G, Feucht MJ, Sudkamp NP, Izadpanah K (2018) Modified Lemaire extra-articular stabilisation of the knee for the treatment of anterolateral instability combined with diffuse pigmented villonodular synovitis: a case report. BMC Musculoskelet Disord 19(1):330
14. Getgood A, Bryant D, Firth A, Stability G (2019) The Stability study: a protocol for a multicenter randomized clinical trial comparing anterior cruciate ligament reconstruction with and without Lateral extra-articular tenodesis in individuals who are at high risk of graft failure. BMC Musculoskelet Disord 20(1):216

15. Gurpinar T, Polat B, Polat AE, Mutlu IN, Tuzuner T (2018) Is anterolateral ligament rupture a reason for persistent rotational instability after anterior cruciate ligament reconstruction? Knee 25(6):1033-1039

16. Helito CP, Sobrado MF, Giglio PN et al (2019) Combined reconstruction of the anterolateral ligament in patients with anterior cruciate ligament injury and ligamentous hyperlaxity leads to better clinical stability and a lower failure rate than isolated anterior cruciate ligament reconstruction. Arthroscopy 35(9):2648-2654

17. Irrgang JJ, Anderson AF, Boland AL et al (2001) Development and validation of the international knee documentation committee subjective knee form. Am J Sports Med 29(5):600-613

18. Isberg J, Faxen E, Brandsson S, Eriksson BI, Karrholm J, Karlsson J (2006) KT-1000 records smaller side-to-side differences than radiostereometric analysis before and after an ACL reconstruction. Knee Surg Sports Traumatol Arthrosc 14(6):529-535

19. Jaecker V, Shafizadeh S, Naendrup JH, Ibe P, Herbort M, Pfeiffer TR (2020) Tactile techniques are associated with a high variability of tunnel positions in lateral extra-articular tenodesis procedures. Arch Orthop Trauma Surg 140(4):495-501

20. Kahlenberg CA, Nwachukwu BU, Mehta N et al (2020) Development and validation of the hospital for special surgery anterior cruciate ligament postoperative satisfaction survey. Arthroscopy. https://doi.org/10.1016/j.arthro.2020.02.043

21. Kellgren JH, Lawrence JS (1957) Radiological assessment of osteo-arthrosis. Ann Rheum Dis 16(4):494-502

22. Kunze KN, Manzi J, Richardson M et al (2021) Combined anterolateral and anterior cruciate ligament reconstruction improves pivot shift compared to isolated anterior cruciate ligament reconstruction: a systematic review and meta-analysis of randomized controlled trials. Arthroscopy. https://doi.org/10.1016/j. arthro.2021.03.058

23. Lee DW, Lee JK, Kwon SH et al (2021) Adolescents show a lower healing rate of anterolateral ligament injury and a higher rotational laxity than adults after anterior cruciate ligament reconstruction. Knee 30:113-124

24. Mayr HO, Benecke P, Hoell A et al (2016) Single-bundle versus double-bundle anterior cruciate ligament reconstruction: a comparative 2-year follow-up. Arthroscopy 32(1):34-42

25. Mayr HO, Bruder S, Hube R, Bernstein A, Suedkamp NP, Stoehr A (2018) Single-bundle versus double-bundle anterior cruciate ligament reconstruction-5-year results. Arthroscopy 34(9):2647-2653

26. Mayr HO, Hoell A, Bernstein A et al (2011) Validation of a measurement device for instrumented quantification of anterior translation and rotational assessment of the knee. Arthroscopy 27(8):1096-1104

27. Mehl J, Otto A, Baldino JB et al (2019) The ACL-deficient knee and the prevalence of meniscus and cartilage lesions: a systematic review and meta-analysis (CRD42017076897). Arch Orthop Trauma Surg 139(6):819-841

28. Moewis P, Duda GN, Jung T, et al. (2016) The Restoration of Passive Rotational Tibio-Femoral Laxity after Anterior Cruciate Ligament Reconstruction. PLoS One, 11(7):e0159600

29. Naendrup JH, Zlotnicki JP, Murphy CI, Patel NK, Debski RE, Musahl V (2019) Influence of knee position and examinerinduced motion on the kinematics of the pivot shift. J Exp Orthop 6(1): 11

30. Nielsen ET, Stentz-Olesen K, de Raedt S et al (2018) Influence of the anterolateral ligament on knee laxity: a biomechanical cadaveric study measuring knee kinematics in 6 degrees of freedom 
using dynamic radiostereometric analysis. Orthop J Sports Med 6(8):2325967118789699

31. Noyes FR, Grood ES, Cummings JF, Wroble RR (1991) An analysis of the pivot shift phenomenon. The knee motions and subluxations induced by different examiners. Am J Sports Med 19(2): 148-155

32. Noyes FR, Huser LE, West J, Jurgensmeier D, Walsh J, Levy MS (2018) Two different knee rotational instabilities occur with anterior cruciate ligament and anterolateral ligament injuries: a robotic study on anterior cruciate ligament and extra-articular reconstructions in restoring rotational stability. Arthroscopy 34(9):2683-2695

33. Olewnik L, Gonera B, Kurtys K et al (2018) The anterolateral ligament of the knee: a proposed classification system. Clin Anat 31(7):966-973

34. Ra HJ, Kim JH, Lee DH (2020) Comparative clinical outcomes of anterolateral ligament reconstruction versus lateral extra-articular tenodesis in combination with anterior cruciate ligament reconstruction: systematic review and meta-analysis. Arch Orthop Trauma Surg 140(7):923-931

35. Roessler PP, Schuttler KF, Heyse TJ, Wirtz DC, Efe T (2016) The anterolateral ligament (ALL) and its role in rotational extraarticular stability of the knee joint: a review of anatomy and surgical concepts. Arch Orthop Trauma Surg 136(3):305-313

36. Rowan FE, Huq SS, Haddad FS (2019) Lateral extra-articular tenodesis with ACL reconstruction demonstrates better patientreported outcomes compared to ACL reconstruction alone at 2 years minimum follow-up. Arch Orthop Trauma Surg 139(10):1425-1433

37. Saita Y, Schoenhuber H, Thiebat G et al (2019) Knee hyperextension and a small lateral condyle are associated with greater quantified antero-lateral rotatory instability in the patients with a complete anterior cruciate ligament (ACL) rupture. Knee Surg Sports Traumatol Arthrosc 27(3):868-874

38. Saithna A, Thaunat M, Delaloye JR, Ouanezar H, Fayard JM, Sonnery-Cottet B (2018) Combined ACL and Anterolateral Ligament Reconstruction. JBJS Essent Surg Tech, 8(1):e2

39. Slichter ME, Wolterbeek N, Auw Yang KG, Zijl JAC, Piscaer TM (2018) A novel test for assessment of anterolateral rotatory instability of the knee: the tibial internal rotation test (TIR test). J Exp Orthop 5(1):29

40. Slichter ME, Wolterbeek N, Auw Yang KG, Zijl JAC, Piscaer TM (2018) Rater agreement reliability of the dial test in the ACLdeficient knee. J Exp Orthop 5(1):18

41. Song Y, Yang JH, Choi WR, Lee JK (2019) Magnetic resonance imaging-based prevalence of anterolateral ligament abnormalities and associated injuries in knees with acute anterior cruciate ligament injury. J Knee Surg 32(9):866-871

42. Sonnery-Cottet B, Lutz C, Daggett M et al (2016) The involvement of the anterolateral ligament in rotational control of the knee. Am J Sports Med 44(5):1209-1214

43. Sonnery-Cottet B, Vieira TD, Ouanezar H (2019) Anterolateral ligament of the knee: diagnosis, indications, technique. Outcomes Arthroscopy 35(2):302-303

44. Tsai AG, Musahl V, Steckel H et al (2008) Rotational knee laxity: reliability of a simple measurement device in vivo. BMC Musculoskelet Disord 9:35

45. Ueki H, Katagiri H, Otabe K et al (2019) Contribution of additional anterolateral structure augmentation to controlling pivot shift in anterior cruciate ligament reconstruction. Am J Sports Med 47(9):2093-2101

46. Weiler A, Schmeling A, Stohr I, Kaab MJ, Wagner M (2007) Primary versus single-stage revision anterior cruciate ligament reconstruction using autologous hamstring tendon grafts: a prospective matched-group analysis. Am J Sports Med 35(10):1643-1652

47. Wroble RR, Grood ES, Cummings JS, Henderson JM, Noyes FR (1993) The role of the lateral extraarticular restraints in the anterior cruciate ligament-deficient knee. Am J Sports Med 21(2):257-262 (Discussion 263)

48. Zens M, Feucht MJ, Ruhhammer J et al (2015) Mechanical tensile properties of the anterolateral ligament. J Exp Orthop 2(1):7

49. Zens M, Niemeyer P, Bernstein A et al (2015) Novel approach to dynamic knee laxity measurement using capacitive strain gauges. Knee Surg Sports Traumatol Arthrosc 23(10):2868-2875

Publisher's Note Springer Nature remains neutral with regard to jurisdictional claims in published maps and institutional affiliations. 